(C) 2019. This manuscript version is made available under the CC-BY-NC-ND 4.0 license http://

creativecommons.org/licenses/by-nc-nd/4.0/

\section{1}

2

\title{
A Further Verification of FZI* and PSRTI: Newly Developed Petrophysical
} Rock Typing Indices

\author{
Abouzar Mirzaei-Paiaman ${ }^{1, *}$, Fereshteh Sabbagh ${ }^{1}$, Mehdi Ostadhassan $^{2}$, Ali Shafiei $^{3}$, Reza \\ Rezaee $^{4}$, Hadi Saboorian-Jooybari ${ }^{5}$, Zhangxin Chen ${ }^{5}$ \\ ${ }^{1}$ Department of Petroleum Engineering, National Iranian South Oil Company, Ahvaz, Iran \\ ${ }^{2}$ Petroleum Engineering Department, University of North Dakota, Grand Forks, ND 58201, USA \\ ${ }^{3}$ Department of Petroleum Engineering, Nazarbayev University, Astana, 010000, Republic of Kazakhstan \\ ${ }^{4}$ Department of Petroleum Engineering, Curtin University, Perth 6151, Australia \\ ${ }^{5}$ Department of Chemical and Petroleum Engineering, Schulich School of Engineering, University of Calgary, 2500 \\ University Drive NW, Calgary, AB, Canada T2N 1N4
}

*Corresponding author: Mirzaei1986@gmail.com, Mirzaei.a@nisoc.ir, Tel.:+989168014851

\begin{abstract}
Despite the differences between petrophysical static (PSRTs) and dynamic rock types (PDRTs), previous indices were unable to distinguish between them. FZI-Star (FZI*) and PSRTI are recently developed petrophysical dynamic and static rock typing indices, respectively. Considering the importance of rock typing in reservoir characterization and the need for reliable and user-friendly techniques, in this study we attempt to further verify the performance of FZI* and PSRTI by comparing them with FZI, Winland r35, and MFZI using data belonging to a heterogeneous carbonate reservoir from the Asmari Formation. The experimental data set includes 10 primary drainage mercury injection, 29 water-oil, and 45 gas-oil capillary pressure tests for PSRTs prediction in conjunction with 52 water-oil and 51 gas-oil relative permeability data for PDRTs. Moreover, we investigated the correlation between various indices and several petrophysical attributes. We defined these attributes as the integrals of mercury injection capillary pressure, mercury injection threshold capillary pressure, measured r35, capillary pressure, and relative permeability curves along with residual saturations. The results showed that our indices are able to successfully identify static and dynamic rock units with higher accuracy than other indices. Among the other existing methods, Winland r35 was the only one that showed an acceptable outcome; while, FZI, and MFZI underperformed in identifying the existing rock types. Using the experimental data we also propose the empirical equations that can be used to model capillary pressure and relative permeability characteristics of rocks.
\end{abstract}


32 Keywords: Petrophysics, Rock typing, FZI-Star (FZI*), PSRTI, Winland r35, FZI

\section{Nomenclature and list of symbols}

34 Acronyms or Abbreviations

35 DRT

Discrete Rock Type

$36 \quad$ FZI

Flow Zone Indicator

$37 \quad$ FZI*

FZI-Star (a modified flow zone indicator)

$38 \quad \mathrm{FZI} * *$

FZI-Double Star (a modified flow zone indicator)

$39 J$-function

A normalized capillary pressure function

40 LC

Lorenz Coefficient

$41 \quad$ MFZI

Modified Flow Zone Indicator

42 PDRT

Petrophysical Dynamic Rock Type

43 PSRT

Petrophysical Static Rock Type

$44 \quad$ PSRTI

Petrophysical Static Rock Type Indicator

45 SCAL

Special Core Analysis Laboratory

46 Symbols

$47 \quad \mathrm{C}_{1}$ to $\mathrm{C}_{13}$

Constant

$48 \quad \frac{\mathrm{dp}}{\mathrm{dx}}$

Pressure change per unit length of a porous medium

$49 \quad \mathrm{~F}_{\mathrm{S}}$

Shape factor

$50 \quad \mathrm{k}_{\mathrm{e}}$

Effective permeability

$51 \quad \mathrm{k}_{\mathrm{eg}}$

Gas effective permeability

$52 \quad \mathrm{k}_{\mathrm{eo}}$

Oil effective permeability

$53 \mathrm{k}_{\mathrm{ew}}$

Water effective permeability

$54 \quad \mathrm{k}_{\mathrm{r}}$

Relative permeability

$55 \quad \mathrm{P}_{\mathrm{c}, \mathrm{g}-\mathrm{o}}$

Gas-oil capillary pressure 


$\begin{array}{lll}56 & \mathrm{P}_{\mathrm{c}, \mathrm{Hg}} & \text { Mercury injection capillary pressure } \\ 57 & \mathrm{P}_{\mathrm{c}, \mathrm{W}-\mathrm{o}} & \text { Water-oil capillary pressure } \\ 58 & \mathrm{r}_{\mathrm{mh}} & \text { Effective or mean hydraulic unit radius } \\ 59 & \mathrm{~S}_{\mathrm{Hg}} & \text { Mercury saturation } \\ 60 & \mathrm{~S}_{\mathrm{o}} & \text { Oil saturation } \\ 61 & \mathrm{~S}_{\mathrm{oi}} & \text { Initial oil saturation } \\ 62 & \mathrm{~S}_{\mathrm{or}} & \text { Wesidual oil saturation } \\ 63 & \mathrm{~S}_{\mathrm{w}} & \text { Connate water saturation } \\ 64 & \mathrm{~S}_{\mathrm{wc}} & \text { Capillary pressure } \\ 65 & P_{c} & \text { Fluid velocity or interstitial velocity } \\ 66 & \mathrm{v} & \text { Tortuosity } \\ 67 & \tau & \text { Effective connected porosity } \\ 68 & \phi & \text { Constant } \\ 69 & A & \text { Absolute permeability } \\ 70 & k & \end{array}$

\section{1. Introduction}

72 Petrophysical rock typing has a broad range of applications in drilling (e.g., prediction of high 73 fluid-loss zones), production (e.g., identifyig potential production/injection zones for locating 74 perforations, and designing diversion systems in acidizing) (Roque et al., 2017; Oliveira et al., 75 2016), reservoir studies (net-pay cut-off definition) (Kolodzie, 1980; Saboorian-Jooybari, 2017), 76 and permeability prediction in un-cored intervals (Amaefule et al., 1993; Abbaszadeh et al., 77 1996; Chen and Yao, 2017; Chen and Zhou, 2017). However, its reservoir engineering-related 78 applications such as representative sample selection for special core analysis (SCAL) tests 79 (Siddiqui et al., 2006, Serag El-Din et al., 2014, Mirzaei-Paiaman and Saboorian-Jooybari, 2016; 80 Mirzaei-Paiaman et al., 2018), and defining saturation functions for reservoir static/dynamic 81 modeling (Mirzaei-Paiaman et al., 2015 and 2018; Askari and Behrouz, 2011) are more 82 signifcant since the outcomes directly affect the simulation models output and their reliability. 
For instance, rock typing can efficiently reduce the number of representative samples required for SCAL analysis (Mirzaei-Paiaman and Saboorian-Jooybari, 2016). Furthermore, assigning saturation functions to static and dynamic reservoir models requires establishing a clear relationship between saturation functions and laboratory measured rock properties.

So far, it has been assumed that a given rock type can be represented by a unique primary drainage capillary pressure profile along with a set of relative permeability curves (SaboorianJooybari et al. 2010; Izadi and Ghalambor, 2013; Ferreira et al., 2015; Mirzaei-Paiaman et al., 2015). However, we showed recently (Mirzaei-Paiaman et al., 2018) that rocks with a unique primary drainage capillary pressure profile might have a different set of relative permeability curves and vice-versa depending on complexity of the porous medium regardless of wetting conditions. Thus, each saturation function may need a particular rock typing scheme. This led to defining a new petrophysical static (PSRT) and a dynamic rock type (PDRT) which proved rock types might not necessarily overlap or share petrophysical properties, no matter what their wettability is (Mirzaei-Paiaman et al., 2018).

Each petrophysical rock type should be characterized using a quantitative index with routine core data as an input. This facilitates categorization of rock types and can be considered as a more efficient sample selection for SCAL tests. Such a procedure enables us to assign the corresponding saturation functions to the static and dynamic reservoir models. In this regard, core-based petrophysical rock typing methods were classified into three categories (MirzaeiPaiaman et al., 2018) as follows:

1. Indices that utilize permeability, porosity, and connate water saturation such as cut-off based methods (Rebelle, 2014), empirical (Kolodzie, 1980; Pittman, 1992; Aguilera, 2002) or theoretical ones (Amaefule et al., 1993; Mirzaei-Paiaman et al., 2015, 2018).

2. Capillary pressure-based methods such as $J$-functions, the empirical $P_{c}$ grouping technique, parameterization (Thomeer, 1960; Xu and Torres-Verdín, 2013; Lin et al., 2015), and measured r35 (Kolodzie, 1980).

3. Spontaneous imbibition rate-driven method of FZI** or "FZI-Double Star" developed by Mirzaei-Paiaman and Saboorian-Jooybari (2016).

Among these, the first category is of special interest since it generally does not require prior knowledge of capillary pressure and/or relative permeability data, but to some extent uses SCAL-driven parameters (Nooruddin and Hossain, 2011; Izadi and Ghalambor, 2013). Despite 
114 the differences between PSRT and PDRT, current indices are not able to distinguish between 115 static and dynamic rock types (Mirzaei-Paiaman et al., 2018). Furthermore, since theoretical 116 indices (Amaefule et al., 1993; Nooruddin and Hossain, 2011; Izadi and Ghalambor, 2013) are 117 mainly based on a generalized form of the Kozeny-Carman equation, then the outcome (e.g., FZI 118 by Amaefule et al. (1993)) is a function of grain size rather than pore throat diameter. Depending 119 on the pore network complexity, significant errors can be introduced to rock typing results. Also, 120 empirical indices are not universal and are highly dependent on porous medium properties.

121 Considering the importance of rock typing in reservoir characterization and the need for reliable 122 and user-friendly techniques, this study attempts to further verify our newly developed 123 petrophysical rock typing approach (Mirzaei-Paiaman et al., 2018). We presented the consistency 124 of our methodology in delineating static and dynamic rock types and its superiority over existing 125 methods. It is noteworthy that none of the previous rock typing indices (Amaefule et al., 1993; 126 Nooruddin and Hossain, 2011; Izadi and Ghalambor, 2013) had been verified using an 127 exhaustive set of SCAL data. Therefore, we utilized a comprehensive set of SCAL data from a 128 heterogeneous Oligocene-Miocene carbonate reservoir from the Asmari Formation in one of the 129 Iranian SW oil fields to examine their reliability. The experimental data contains 10 primary 130 drainage mercury injection, 29 water-oil and 45 gas-oil capillary pressure tests for PSRTs and 52 131 water-oil and 51 gas-oil relative permeability experiments for PDRTs. In addition to characterize 132 the static and dynamic rock types, we also empirically investigated the correlation between 133 available indices and various petrophysical attributes of the samples.

134 A further useful verification could be presented here which may support Mirzaei-Paiaman et al. 135 (2018) as:

136 1. In Mirzaei-Paiaman et al. (2018), the SCAL data that was used to check the models belonged to a reservoir from Albian-Campanian Bangestan group with a dissimilar depositional environment and diagenetic history to the Oligocene-Miocene Asmari Formation. It is vital to further verify or validate the performance of newly developed models against large sets of high quality and reliable data from various resources especially data from complex reservoir systems. This is the only way to have a closer look at the newly developed models and map their strength (i.e., where they perform better against existing models for certain reservoirs) and possible weakness where they are not superior to the existing models. 
2. The size and variety of the data used for performance analysis and verification is not comparable to Mirzaei-Paiaman et al. (2018). Mirzaei-Paiaman et al. (2018) studied only the SCAL data in oil-water systems, whereas in the present work the systems of gas-oil tests were also utilized. Incorporation of diverse types of fluid systems enables us to enhance the knowledge of different rock typing indices along with their pros and cons. Such hard data are very valuable for other researchers, as well.

3. The empirical models that are used to model the capillary pressure and relative permeability characteristics of rocks are also different from Mirzaei-Paiaman et al. (2018).

\section{FZI-Star (FZI*) and PSRTI}

Using the base form of Kozeny-Carman equation and Darcy's law for single and multiphase flow, an index was introduced to define PDRTs using routine core data (Mirzaei-Paiaman et al., 2018). The base form of Kozeny-Carman equation links the micro-scale characteristics of a porous medium to its permeability and porosity (Kozeny, 1927; Carman, 1937) which can be written as (Mirzaei-Paiaman et al., 2015, 2018):

$$
\mathrm{k}=\phi \frac{\mathrm{r}_{\mathrm{mh}}^{2}}{\mathrm{~F}_{\mathrm{s}} \tau}
$$

where $k$ is the absolute permeability, $\phi$ is the effective connected porosity, $\mathrm{r}_{\mathrm{mh}}$ is the effective or mean hydraulic unit radius (defined as the ratio of a cross-sectional area to a wetted perimeter), $\tau$ is the tortuosity (defined as the ratio of an actual fluid-travelled length to the system length) (Shen and Chen, 2007), and $F_{s}$ is the shape factor to account for non-circular capillary tubes $\left(F_{s}=2\right.$ for a circular tube). $\frac{r_{m h}^{2}}{F_{s} \tau}$ is a pack of microstructural attributes of sedimentary rocks that control the fluid flow which can vary between $\frac{\mathrm{v}}{\mathrm{dp} / \mathrm{dx}}$ values of different rock types ( $\mathrm{v}$ is the fluid velocity or interstitial velocity and $\frac{\mathrm{dp}}{\mathrm{dx}}$ is the pressure change per unit length of a porous medium). When permeability and porosity are in millidarcy $(\mathrm{mD})$ and fraction, respectively; then FZI* can be expressed in microns to define PDRTs as (Mirzaei-Paiaman et al., 2018):

$$
\mathrm{FZI}^{*}=0.0314 \sqrt{\frac{\mathrm{k}}{\phi}}=\frac{\mathrm{r}_{\mathrm{mh}}}{\sqrt{\mathrm{F}_{\mathrm{s}}}}
$$

Samples with similar FZI* values should exhibit comparable fluid flow behavior and thus can be bundled as an individual PDRT. For a given PDRT, cross-plot of $0.0314 \sqrt{\mathrm{k}}$ vs. $\sqrt{\phi}$ on a $\log -\log$ 
173 scale yields a unite-slope line, and the intercept with $\phi=1$ will be the FZI*. In opposite, rocks 174 with different FZI* should appear as a series of parallel lines. Finally, permeability in un-cored 175 intervals can be estimated by:

$$
\mathrm{k}=1014 \phi\left(\mathrm{FZI}^{*}\right)^{2}
$$

177 FZI* can also be directly concluded from Darcy's law for 1-D single-phase fluid flow in a 178 homogeneous porous medium when the Darcy velocity is replaced by interstitial velocity 179 (Mirzaei-Paiaman et al., 2018). In a multiphase flow system, if the fluid properties are kept 180 constant then $\frac{\mathrm{k}_{\mathrm{e}}}{\phi}$ or $\frac{\mathrm{kk}_{\mathrm{r}}}{\phi}$ or $\mathrm{FZI}^{* 2} \mathrm{k}_{\mathrm{r}}$ is the parameter that controls the flow implying that samples with similar flow behavior should present similar $\frac{k k_{r}}{\phi}$ data $\left(\mathrm{k}_{\mathrm{e}}\right.$ and $\mathrm{k}_{\mathrm{r}}$ are the effective and relative permeabilities, respectively). However, this contradicts the common practice in petrophysical rock typing that rocks within one PDRT should have similar relative permeability, $\mathrm{k}_{\mathrm{r}}$, data. Ultimately, $k_{r}$ is a saturation-dependent property and thus FZI* can be assumed as the index that identifies dynamic rock groups in the multiphase flow system when routine core data is available only.

187 Furthermore, a new index for PSRTs was developed through combining the Young-Laplace capillary pressure expression and the base form of Kozeny-Carman equation (Mirzaei-Paiaman et al., 2018) known as PSRTI:

$$
\text { PSRTI }=0.0314 \sqrt{\frac{\mathrm{k}}{\phi} \mathrm{F}_{\mathrm{s}} \tau}=\mathrm{FZI}^{*} \sqrt{\mathrm{F}_{\mathrm{s}} \tau}
$$

When rock-fluid interaction and fluid properties remain unchanged, cores with similar PSRTI values will exhibit similar primary drainage capillary pressure curves and thus form an individual PSRT. In practice, where $\mathrm{F}_{\mathrm{s}} \tau$ is not easy to measure for each rock separately, FZI* becomes the sole parameter to delineate PSRTs depending on pore geometry complexity among the population of rocks.

196 3. Data Collection

197 Petrophysical data is collected on core plugs retrieved from a carbonate reservoir in the Asmari 198 Formation located north of the Persian Gulf, SW Iran. Figure 1 shows the cross-plots of porosity199 permeability and the Lorenz plots for horizontal and vertical plugs. In the porosity-permeability 200 cross-plots the correlation coefficients were 0.63 and 0.78 for horizontal and vertical plugs, respectively. Furthermore, the Lorenz Coefficients (LC) were 0.61 (for horizontal plugs) and 
0.55 (for vertical plugs). The values of these two indices confirm the heterogeneous nature of the reservoir, especially in the horizontal direction.

204

205

206

207

208

209

210

211

212

213

214

215

216
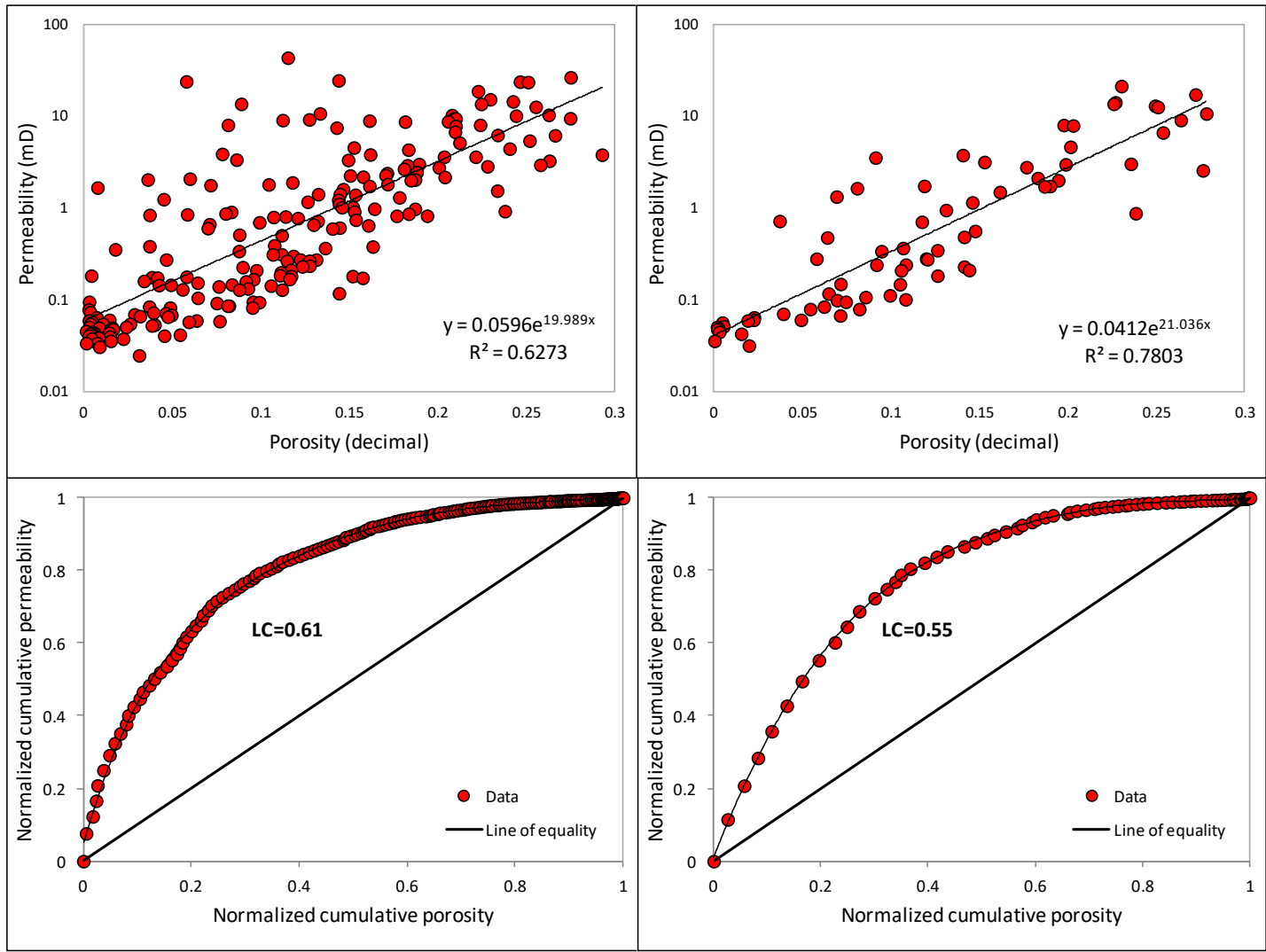

Figure 1. Porosity-permeability cross-plot and Lorenz plot for horizontal (left) and vertical (right) plugs. The data presented indicates highly heterogeneous nature of the carbonate reservoir rock.

\section{Results and Discussion}

\subsection{PSRTs}

\subsubsection{Primary drainage mercury injection capillary pressure data}

In this section, we compare the results from FZI*, FZI, and Winland r35 techniques in defining PSRTs in our samples. FZI (Amaefule et al., 1993) and Winland r35 (Kolodzie, 1980) are expressed in micron, where permeability and porosity are in $\mathrm{mD}$ and fraction, respectively, as follows:

$F Z I=\frac{0.0314 \sqrt{\frac{\mathrm{k}}{\phi}}}{\frac{\phi}{1-\phi}}$

$\log \left(r_{35}\right)=-0.996+0.588 \log (k)-0.864 \log (\phi)$ 
217 The DRT, Discrete Rock Type, equation was used to separate different clusters (Abbaszadeh et. 218 1996; Mirzaei-Paiaman et al., 2018).

219

$$
\text { DRT no. }=\operatorname{ROUND}(\operatorname{LOG}(\text { index })+A ; 0)
$$

220 In this equation, $A$ is an adjustable constant and is chosen in such a way that the output starts 221 from 1 corresponding to the PSRT no. 1 (i.e., PSRT1). $A$ is 2.6 for FZI* and 1.6 for both FZI and 222 Winland r35.

223 The PSRTs that are identified by different methods are shown in Figure 2 where the data before 224 the threshold pressure point is eliminated based on Mirzaei-Paiaman et al. (2018)'s method. In 225 this figure, the DRT numbers 1, 2, and 3 are represented by red, orange, and green, respectively. 226 It can be found from the following figure that although capillary pressure curves are not 227 following similar trends, FZI identifies only one PSRT; while, FZI* and Winland r35 recognize 228 two distinct groups of rock types (PSRT1 above PSRT2). 


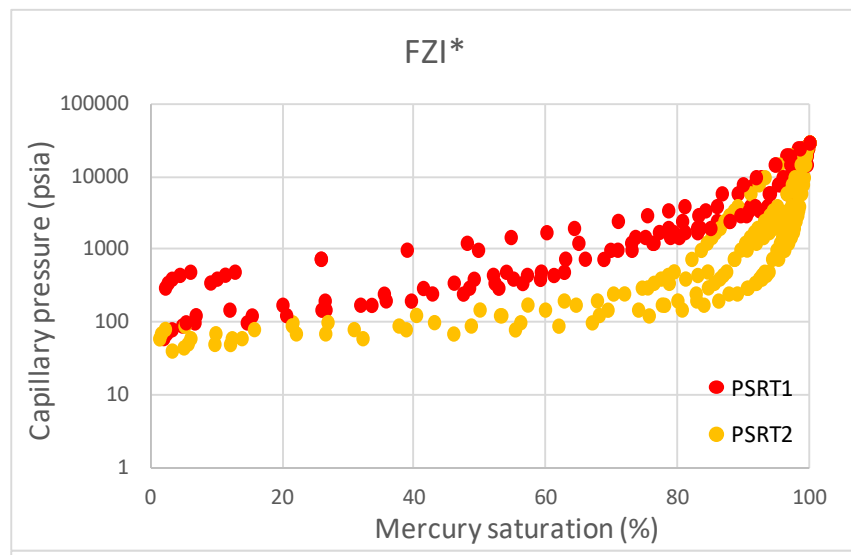

FZI

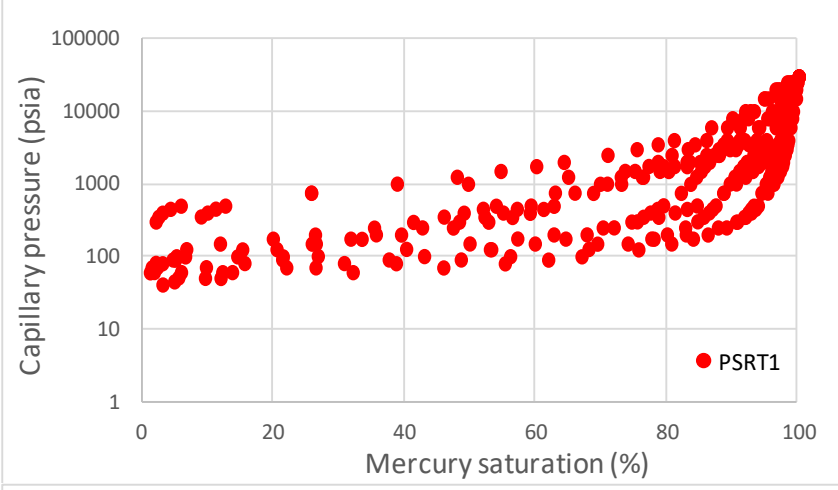

r35

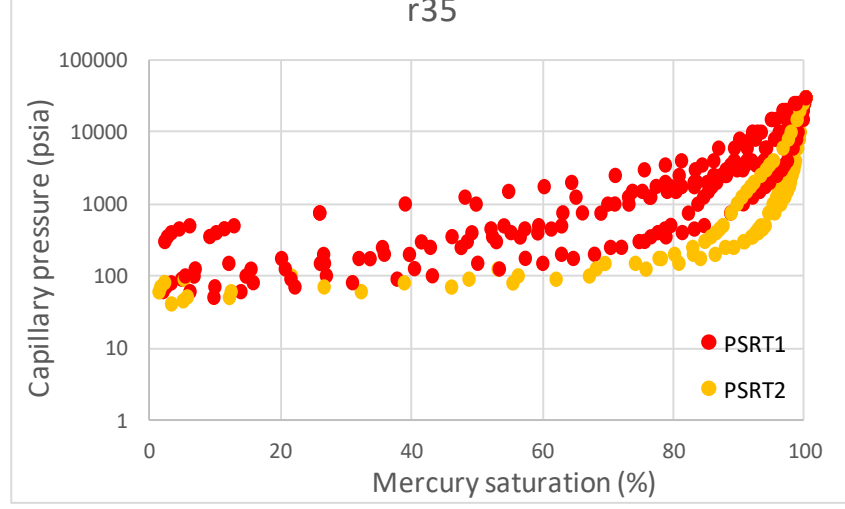

230 Figure 2 Identification of PSRTs using mercury injection capillary pressure data by FZI* (top), FZI (middle), and Winland r35 (bottom).

232 Figure 3 shows incremental mercury saturation vs. a pore throat radius predicted by three 233 different methods. In this process, we did not include capillary pressure values less than the 234 threshold pressure. A pore throat radius is calculated via the Young-Laplace capillary pressure 235 equation where each PSRT must contain a group of rocks with similar pore throat size 236 distributions. Results confirm that FZI* performed better than FZI and Winland r35 to separate 
237 any existing PSRTs. FZI* found more distinct pore throat clusters than Winland r35 on two 238 separate PSRTs; while, FZI recognized only one PSRT.
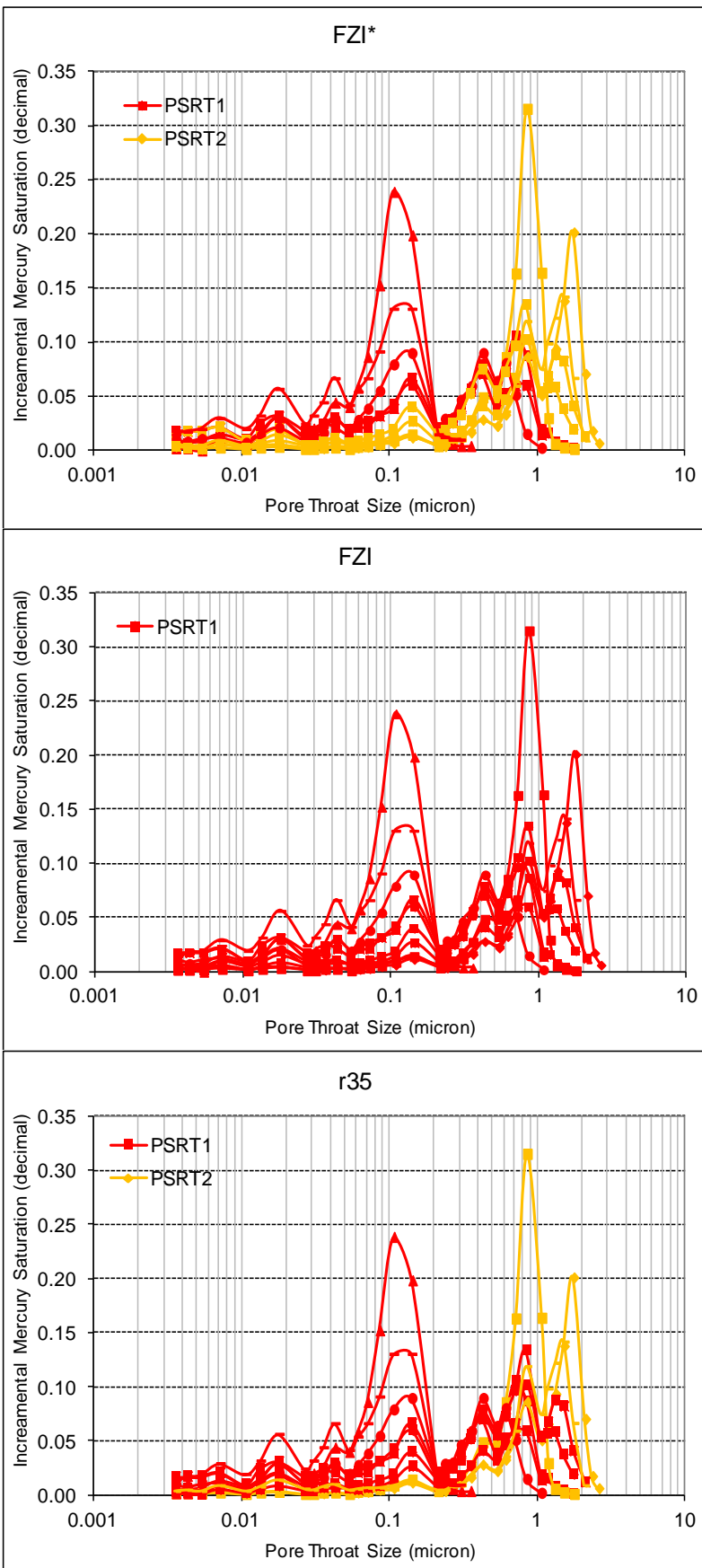

242 The relationship between different indices and the threshold pressure was investigated (see

243 Supplementary Material). It can be found as the threshold pressure increases, both FZI* and

244 Winland r35 decrease with correlation coefficients of 0.66 and 0.61 , respectively. We were not 
able to establish a clear relationship between the threshold pressure and FZI, as the correlation is quite poor mainly because this index is a function of grain size rather than pore throat diameter as previously shown by Mirzaei-Paiaman et al. (2018). In the next step, we plotted different indices vs. measured r35 which is depicted in Supplementary Material. The correlation coefficient between the empirical Winland r35 and the measured $\mathrm{r} 35$ was 0.84 and did not approach unity. This emphasizes the non-universality of this equation; while, the correlation coefficient between FZI* and the measured r35 was 0.84, and FZI and the measured r35 did not exhibit any correlation.

The correlation between these three indices and the area under the capillary pressure curve can be found in Supplementary Material. This area reflects the amount of work that one fluid should do to displace the second fluid through a porous medium (Anderson, 1987). This value is proportional to the pore structure directly. Both FZI* and Winland r35 decrease as the area under the curve increases. This implies that a greater work is needed for fluid displacement. The correlation coefficient was found to be 0.67 and 0.59 for FZI* and Winland r35, respectively. FZI exhibited an opposite trend with a very low correlation coefficient of 0.16 ; where, an increase in the area under the capillary pressure curve resulted in higher FZI values. We investigated the relationship between different attributes of mercury injection capillary pressure data and the indices. This leads to a more precise performance characterization of different indices in rock typing. Later, a quantitative analysis is carried out continuously when dealing with other saturation functions. In the current study, we were also able to demonstrate that saturation functions cannot always be modeled using a specific form of a mathematical function. For example, while an exponential model may give best fit to the relative permeability data of a given formation, it may show poor performance for another formation.

After trying different models, it was found that the mercury injection capillary pressure data could be well represented by an exponential equation (see Table 1). 
Table 1 Details of best fitted models to the data

\begin{tabular}{|c|c|c|c|c|}
\hline \multicolumn{2}{|c|}{ Experiment } & $\begin{array}{c}\text { Best fitted model } \\
\text { type }\end{array}$ & Best fitted model & Comments \\
\hline \multicolumn{2}{|c|}{$\begin{array}{l}\text { Primary drainage mercury } \\
\text { injection capillary pressure } \\
\text { data }\end{array}$} & Exponential & $\mathrm{P}_{\mathrm{c}, \mathrm{Hg}}=\mathrm{C}_{1} \mathrm{e}^{\mathrm{C}_{2} \mathrm{~S}_{\mathrm{Hg}}}$ & $\begin{array}{l}\mathrm{P}_{\mathrm{c}, \mathrm{Hg}} \text { is the measured mercury injection } \\
\text { capillary pressure in psia, } \mathrm{S}_{\mathrm{Hg}} \text { is the } \\
\text { mercury saturation in the core in } \\
\text { fraction and varies from } 0 \text { to } 1 \text {, and } \mathrm{C}_{1} \\
\text { and } \mathrm{C}_{2} \text { are constants }\end{array}$ \\
\hline \multicolumn{2}{|c|}{$\begin{array}{l}\text { Primary drainage water-oil } \\
\text { capillary pressure data }\end{array}$} & Logarithmic & $P_{c, w-o}=-C_{3} \operatorname{Ln}\left(\frac{S_{w}-S_{w c}}{1-S_{w c}}\right)$ & $\begin{array}{l}\mathrm{P}_{\mathrm{c}, \mathrm{w}-\mathrm{o}} \text { is the water-oil capillary } \\
\text { pressure in psia, } \mathrm{C}_{3} \text { is a constant, } \mathrm{S}_{\mathrm{wc}} \text { is } \\
\text { the connate water saturation in fraction, } \\
\text { and } \mathrm{S}_{\mathrm{w}} \text { is the water saturation in } \\
\text { fraction }\end{array}$ \\
\hline \multirow{2}{*}{$\begin{array}{c}\text { Primary } \\
\text { drainage gas- } \\
\text { oil capillary } \\
\text { pressure data }\end{array}$} & $\begin{array}{l}\text { Non-zero } \\
\text { connate } \\
\text { water } \\
\text { saturation }\end{array}$ & Logarithmic & $P_{c, g-o}=-C_{4} \operatorname{Ln}\left(\frac{S_{o}-S_{o r}}{S_{o i}-S_{o r}}\right)$ & $\begin{array}{l}\mathrm{P}_{\mathrm{c}, \mathrm{g}-\mathrm{o}} \text { is the gas-oil capillary pressure } \\
\text { in psia, } \mathrm{C}_{4} \text { is a constant, and } \mathrm{S}_{\mathrm{o}}, \mathrm{S}_{\mathrm{oi}} \text { and } \\
\mathrm{S}_{\mathrm{or}} \text { are the oil saturation, the initial oil } \\
\text { saturation and the residual oil } \\
\text { saturation, respectively in fraction }\end{array}$ \\
\hline & $\begin{array}{l}\text { Zero connate } \\
\text { water } \\
\text { saturation }\end{array}$ & Exponential & $P_{c, g-o}=C_{5} e^{-C_{6}\left(\frac{S_{o}-S_{o r}}{1-S_{o r}}\right)}$ & $\mathrm{C}_{5}$ and $\mathrm{C}_{6}$ are constants \\
\hline \multirow{2}{*}{$\begin{array}{c}\text { Water-oil } \\
\text { relative } \\
\text { permeability } \\
\text { data }\end{array}$} & $\begin{array}{c}\text { Water } \\
\text { relative } \\
\text { permeability } \\
\text { data }\end{array}$ & Exponential & $\frac{\mathrm{k}_{\mathrm{ew}}}{\phi}=\mathrm{C}_{7} \mathrm{e}^{\mathrm{C}_{8} \frac{\mathrm{s}_{\mathrm{w}}-\mathrm{s}_{\mathrm{wc}}}{1-\mathrm{s}_{\mathrm{or}}-\mathrm{S}_{\mathrm{wc}}}}$ & $\begin{array}{c}\mathrm{k}_{\mathrm{ew}} \text { is the water effective permeability } \\
\text { in } \mathrm{mD} \text { and } \mathrm{C}_{7} \text { and } \mathrm{C}_{8} \text { are constants }\end{array}$ \\
\hline & $\begin{array}{c}\text { Oil relative } \\
\text { permeability } \\
\text { data }\end{array}$ & Logarithmic & $\frac{\mathrm{k}_{\mathrm{eo}}}{\phi}=-\mathrm{C}_{9} \operatorname{Ln}\left(\frac{\mathrm{S}_{\mathrm{w}}-\mathrm{S}_{\mathrm{wc}}}{1-\mathrm{S}_{\mathrm{or}}-\mathrm{S}_{\mathrm{wc}}}\right)$ & $\begin{array}{c}\mathrm{k}_{\mathrm{eo}} \text { is the oil effective permeability in } \\
\mathrm{mD} \text { and } \mathrm{C}_{9} \text { is a constant }\end{array}$ \\
\hline \multirow{2}{*}{$\begin{array}{c}\text { Gas-oil } \\
\text { relative } \\
\text { permeability } \\
\text { data }\end{array}$} & $\begin{array}{l}\text { Oil relative } \\
\text { permeability } \\
\text { data }\end{array}$ & Exponential & $\frac{\mathrm{k}_{\mathrm{e} o}}{\phi}=\mathrm{C}_{10} \mathrm{e}^{\mathrm{C}_{11} \frac{\mathrm{S}_{\mathrm{o}}-\mathrm{S}_{\mathrm{or}}}{1-\mathrm{S}_{\mathrm{or}}}}$ & $\mathrm{C}_{10}$ and $\mathrm{C}_{11}$ are constants \\
\hline & $\begin{array}{l}\text { Gas relative } \\
\text { permeability } \\
\text { data }\end{array}$ & Exponential & $\frac{\mathrm{k}_{\mathrm{e} g}}{\phi}=\mathrm{C}_{12} \mathrm{e}^{-\mathrm{C}_{13} \frac{\mathrm{S}_{\mathrm{o}}-\mathrm{S}_{\mathrm{or}}}{1-\mathrm{S}_{\mathrm{or}}}}$ & $\begin{array}{c}\mathrm{k}_{\mathrm{eg}} \text { is the gas effective permeability in } \\
\mathrm{mD} \text { and } \mathrm{C}_{12} \text { and } \mathrm{C}_{13} \text { are constants }\end{array}$ \\
\hline
\end{tabular}

278 The quantitative relationship between three separate indices with $\mathrm{C}_{1}$ and $\mathrm{C}_{2}$ are shown in 279 Supplementary Material. These constants control the capillary pressure curves. FZI* and 280 Winland $\mathrm{r} 35$ showed a decreasing trend as $\mathrm{C}_{1}$ increases implying a higher capillary pressure that 281 is expected in tighter media. The correlation coefficient of 0.05 confirms there is not a clear 
282 relationship between such attributes and FZI. Both FZI* and Winland r35 increased as $\mathrm{C}_{2}$ 283 increased with acceptable correlation coefficients. Likewise there was not any clear relationship 284 between $\mathrm{C}_{2}$ and FZI which means this index is suffering from lack of considering capillary 285 pressure effects.

\section{4.1.2. Primary drainage water-oil capillary pressure data}

287 In addition to FZI*, FZI, and Winland r35, we examined the accuracy of MFZI (Izadi and 288 Ghalambor, 2013). This specific index needs a connate water saturation value, $\mathrm{S}_{\mathrm{wc}}$, as an input 289 parameter. To obtain MFZI, $A=1.6$ was assigned to our data for DRT calculations:

$$
\text { MFZI }=\frac{0.0314 \sqrt{\frac{\mathrm{k}}{\phi}} \times \sqrt{1-\mathrm{S}_{\mathrm{wc}}}}{\frac{\phi}{1-\phi}\left(1-S_{\mathrm{wc}}\right)^{2}}
$$

291 Figure 4 presents the PSRTs that are categorized by each method. FZI*, FZI, and Winland r35, 292 each recognized two PSRTs whereas MFZI recognized three PSRTs. Among all, the indices that 293 produced meaningful groups are FZI* and Winland r35. The PSRT1 that is predicted by FZI* is 294 located reasonably to the right of PSRT2 meaning that at a given water saturation, the tight rocks 295 within PSRT1 need a higher displacement pressure. These tight samples are associated with 296 higher connate water saturations, as well. In terms of recognizing distinct clusters, Winland r35 297 provided us with acceptable predictions, too, however, FZI* is superior. Additionally, FZI and 298 MFZI were unsuccessful in categorizing PSRTs and the identified PSRTs by these two methods 299 did not show separate distinct clusters. 

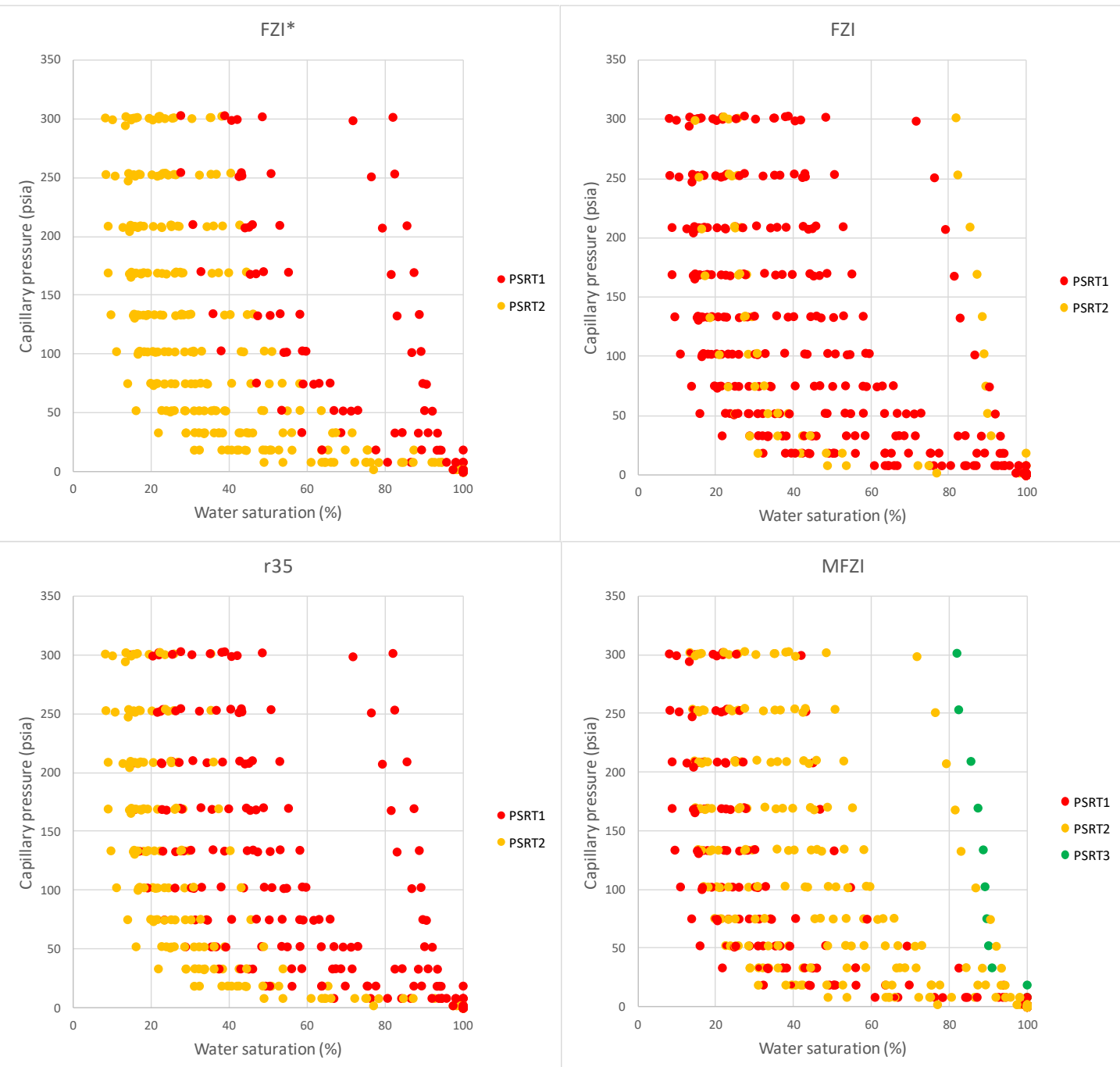

Figure 4 Identification of PSRTs using water-oil capillary pressure data by FZI* (top left), FZI (top right), MFZI (bottom right), and Winland r35 (bottom left).

As discussed earlier, tighter rocks should exhibit higher connate water saturations regardless of wettability (Mirzaei-Paiaman et al., 2013). This means as connate water saturation increases if the right rock typing index is chosen, the index should decrease. Hence, we decided to plot different indices vs. connate water saturation, in particular as shown in Supplementary Material for further verifications. Both FZI* and Winland $\mathrm{r} 35$ followed the expected trend with $\mathrm{R}^{2}$ of 0.58 and 0.48 , respectively. However, FZI did not demonstrate any meaningful correlation with connate water saturation $\left(\mathrm{R}^{2}=0.03\right)$, and MFZI displayed an opposite trend compared to all, with $\mathrm{R}^{2}$ of 0.57 . It should be noted that the MFZI contains the term $\mathrm{S}_{\mathrm{wc}}$.

The quantitative relationship between characteristics of a water-oil capillary pressure curve and different indices was studied, as well. Based on Table 1, logarithmic function represented the 
313 data. The relationship between $\mathrm{C}_{3}$ and various indices is shown in Supplementary Material. In

314 this regard, FZI* and Winland r35 decreased as $\mathrm{C}_{3}$ increased and a closer look at the 315 mathematical equation that was used confirmed the results. In this case, FZI* generated a higher

$316 \mathrm{R}^{2}$ of 0.53 compared to 0.47 for Winland $\mathrm{r} 35$. There is not any meaningful relationship between

$317 \mathrm{C}_{3}$ and FZI (i.e., $\mathrm{R}^{2}$ of 0.04 ). Also, MFZI demonstrated a trend opposite to FZI* and Winland $318 \mathrm{r} 35$, with $\mathrm{R}^{2}$ of 0.20 .

\section{4.1.3. Primary drainage gas-oil capillary pressure data}

\subsubsection{Gas-oil capillary pressure data (non-zero connate water saturation)}

321 The ability of different indices in revealing various PSRTs is demonstrated in Figure 5 where all 322 indices predicted the existence of two separate data clusters with clear distinction. In this figure, the liquid saturation is the sum of the oil and connate water saturations.
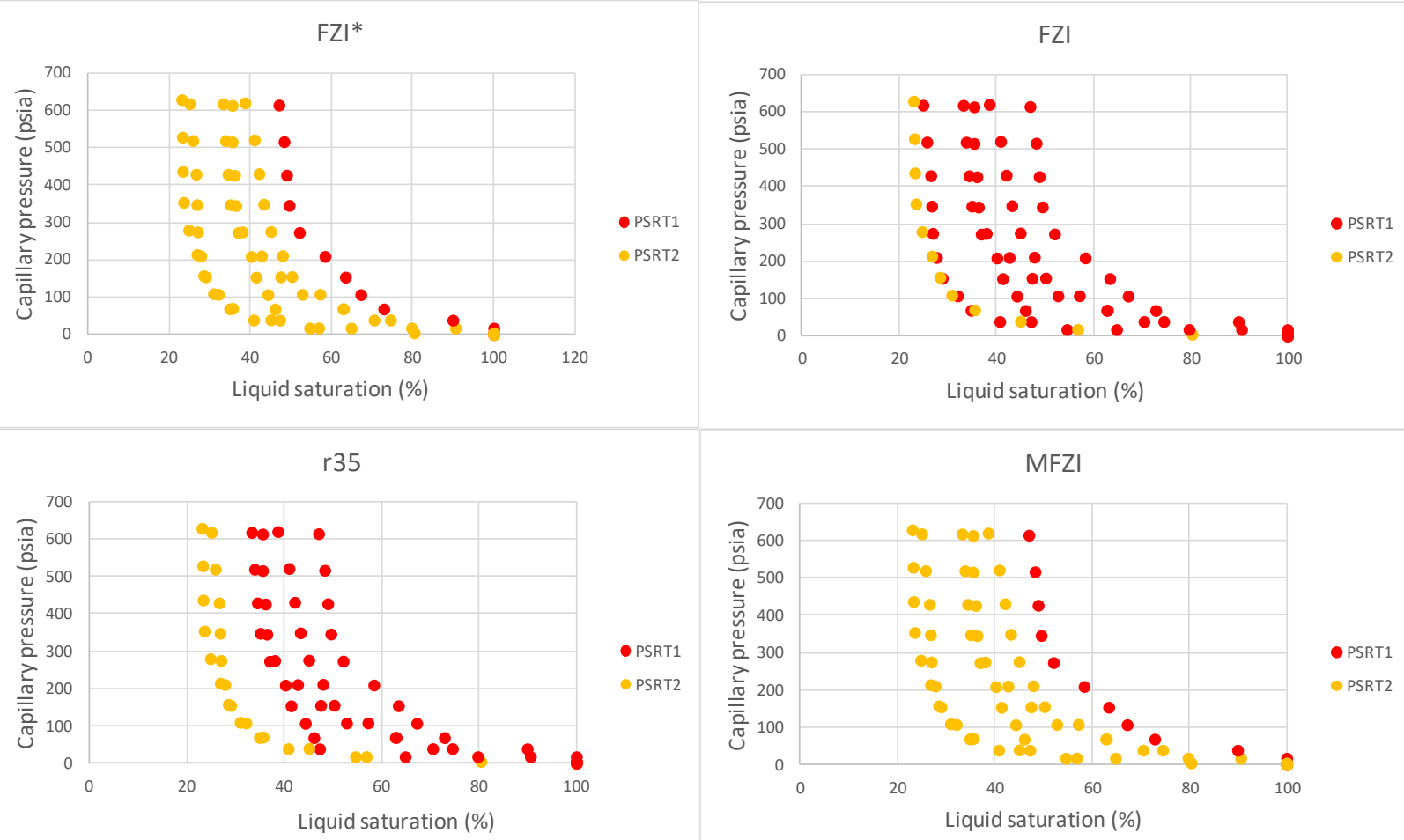

Figure 5 Identification of PSRTs using gas-oil capillary pressure data (with connate water saturation) by FZI* (top left), FZI (top right), MFZI (bottom right) and Winland r35 (bottom left).

Four different indices are plotted vs. residual liquid saturation which is obtained after the primary drainage process (see Supplementary Material). Tight rocks are in general associated with higher residual liquid saturations, which is due to their smaller pore throat sizes (Hamidpour et al., 2015; Mirzaei-Paiaman et al., 2010; Harimi et al., 2018). All indices decreased as residual 
332 liquid saturation increased. This is in accordance with the expected trend between tightness of 333 porous medium pore throat and residual liquid saturation. FZI* and Winland r35 showed a very 334 strong correlation with residual liquid saturation with $\mathrm{R}^{2}$ of 0.97 for both, followed by FZI with $335 \mathrm{R}^{2}$ of 0.93 and MFZI with $\mathrm{R}^{2}$ of 0.73 .

336 The quantitative relationship between parameters of a gas-oil capillary pressure curve and 337 different indices was also analyzed and it was found that a logarithmic function can represent the 338 data (see Table 1). The relationship between $\mathrm{C}_{4}$ and various indices is found in Supplementary 339 Material. It is evident that all indices decrease as $\mathrm{C}_{4}$ increases and this is in line with 340 mathematical form of the fitted function. FZI* and Winland $\mathrm{r} 35$ had the highest correlation 341 coefficients of 0.52 and 0.51 , respectively; whereas, FZI and MFZI yielded $R^{2}$ of 0.29 and 0.11 , 342 correspondingly.

\section{4.1.3.2.Gas-oil capillary pressure data (zero connate water saturation)}

344 Figure 6 explains the PSRTs that are characterized from different indices. Although all indices 345 identified two groups of rocks, FZI* and Winland r35 generated the best results. These two 346 PSRTs that are recognized are mostly separate from one another with some overlaps. FZI and 347 MFZI were incapable of classifying two distinct PSRTs with a clear boundary. 

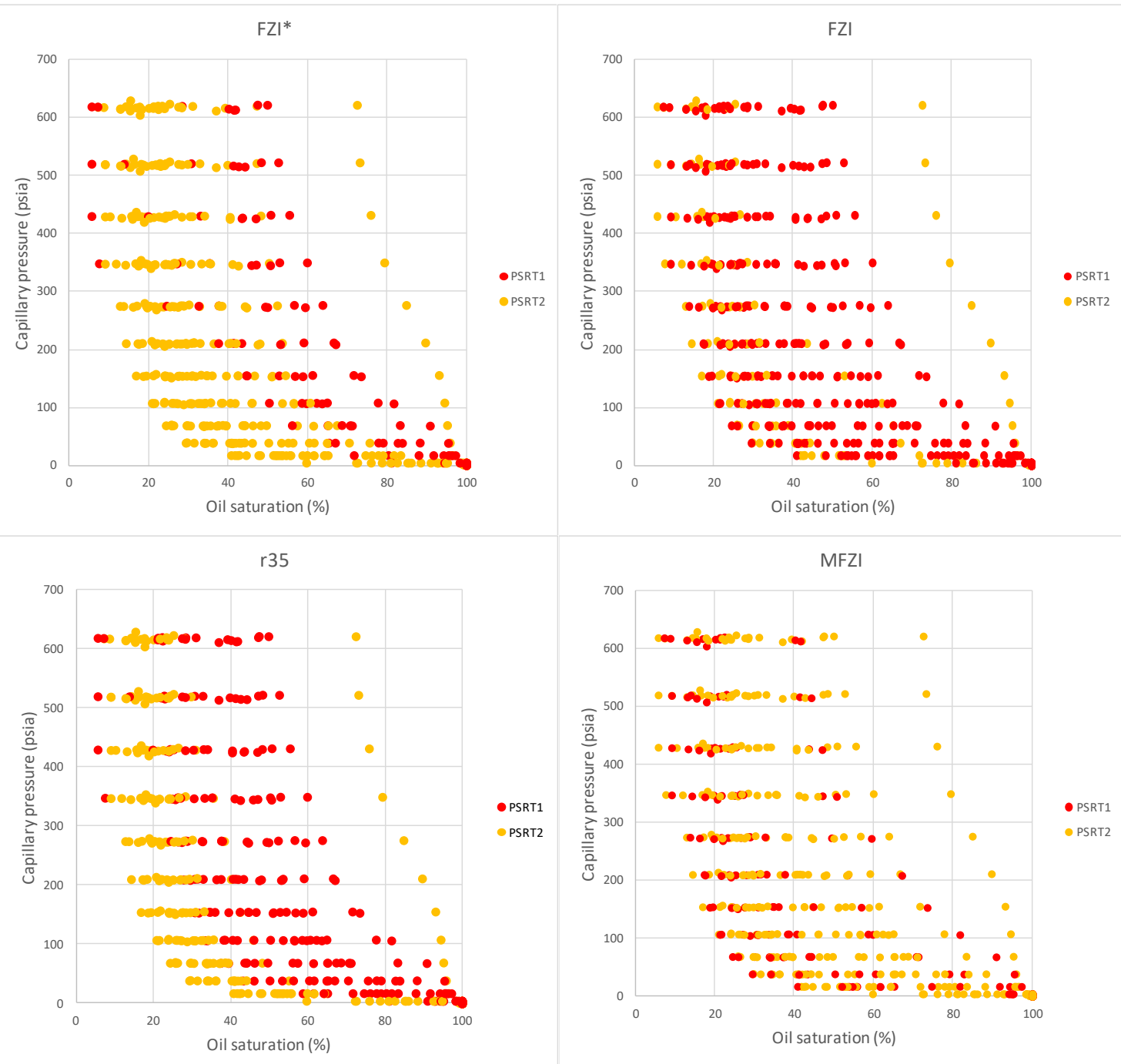

Figure 6 PSRTs using the gas-oil capillary pressure data (zero connate water saturation) by FZI*

(top left), FZI (top right), MFZI (bottom right), and Winland r35 (bottom left).

351 We further analyzed the relationship between the indices and residual oil saturation which is

352 depicted in Supplementary Material. Based on the earlier discussions in this text, a tight porous

353 medium is associated with higher residual oil saturation values. Considering this, all indices,

354 except for the MFZI, decreased as residual oil saturation increased. FZI* and Winland r35

355 showed a correlation coefficient of 0.2 (each), whereas the $\mathrm{R}^{2}$ of FZI was found 0.12 . MFZI

356 provided the highest $\mathrm{R}^{2}$ of 0.33 which is mostly due to the fact that MFZI takes into

357 consideration the connate water saturation term in its formula. It should be noted here that the

358 term residual oil saturation was used instead of connate water saturation to calculate MFZI in our

359 primary drainage gas-oil capillary pressure experiments with zero connate water saturation. 
The exponential model exhibited the best fit (see Table 1) to our data and the plot of each index vs. $\mathrm{C}_{5}$ is shown in Supplementary Material. This relationship signifies the FZI* with $\mathrm{R}^{2}$ of 0.64 followed by Winland $\mathrm{r} 35$ with $\mathrm{R}^{2}$ of 0.55 where both decrease as $\mathrm{C}_{5}$ increases. The correlation between FZI and $\mathrm{C}_{5}$ was quite poor $\left(\mathrm{R}^{2}\right.$ of 0.01$)$. MFZI with $\mathrm{R}^{2}$ of 0.2 exhibited an increasing trend unlike FZI* and Winland r35.

Supplementary Material represents the plots of four different indices vs. $\mathrm{C}_{6}$, as well, where all indices except MFZI showed an increase with respect to $\mathrm{C}_{6}$ with $\mathrm{R}^{2}$ values of $0.44,0.45,0.19$, and 0.07 for FZI*, Winland r35, FZI, and MFZI, respectively.

To develop a mathematical expression for FZI* and PSRTI, porous medium was assumed as a simple bundle of capillary tubes (Mirzaei-Paiaman et al., 2018). Such an assumption may not fully represent or capture the complexities associated with porous medium. Nevertheless, even with such simplified models if properly defined, they can resolve challenging petrophysical problems in highly heterogeneous porous media such as carbonates. Considering the application of FZI* in categorizing various existing PSRTs in a medium, the observed anomalies could have originated from lack of $\mathrm{F}_{\mathrm{s}} \tau$ data in particular. As it was explained earlier, a correct index (i.e., PSRTI) that should be used to study PSRTs ideally is FZI* $\sqrt{F_{s} \tau}$ instead of FZI*. If one can obtain an accurate estimation of $\mathrm{F}_{\mathrm{s}} \tau$ and include it in the analysis, such ambiguities and inconsistencies can be resolved, notably.

Another major reason for the underperformance of FZI* in the appraisal of PSRTs could be due to issues with sample preparation. We assumed that the samples were properly cleaned from drilling fluids and other contaminations prior to experiments to make sure they exhibited the same wetting conditions. However, in practice the cleaning process may still leave behind some contaminations in the samples causing slightly different wettability.

Additionally, if connected porosity is utilized for calculations instead of the effective connected porosity, some overlaps in identified PSRTs, and also PDRTs, can be observed. To be more specific, connected porosity is the one that is measured routinely in laboratory studies and accounts for all connected pore/pore throat sizes, even those small ones that are not contributing to the flow; whereas, effective connected porosity only represents connected pore throats that significantly control the fluid flow through a medium. Hence, if one can measure effective connected porosity and substitute that for connected porosity, better results in petrophysical rock typing will be achieved (Rabiller, 2017; Mirzaei-Paiaman et al., 2018). 


\subsection{Characterization of PDRTs}

\section{2 \\ 4.2.1. Water-oil relative permeability data}

393 PDRTs were investigated by water and oil relative permeability data based on different indices in 394 Figures 7 and 8 . These figures illustrate the strong superiority of FZI* compared to the other methods examined. Despite the fact that PDRTs categorized with this method are well separated, there still exists some areas of overlapping rock types. The reason behind this could be attributed to the use of connected porosity instead of effective connected porosity. Furthermore, aging procedures can generate systems with different wetting conditions. This being said, we should emphasize that FZI* was developed with the assumption of the same wettability among the samples (Mirzaei-Paiaman et al., 2018). Winland r35 also presented a good classification of the

401 PDRTs; while, FZI and MFZI did not produce acceptable results.
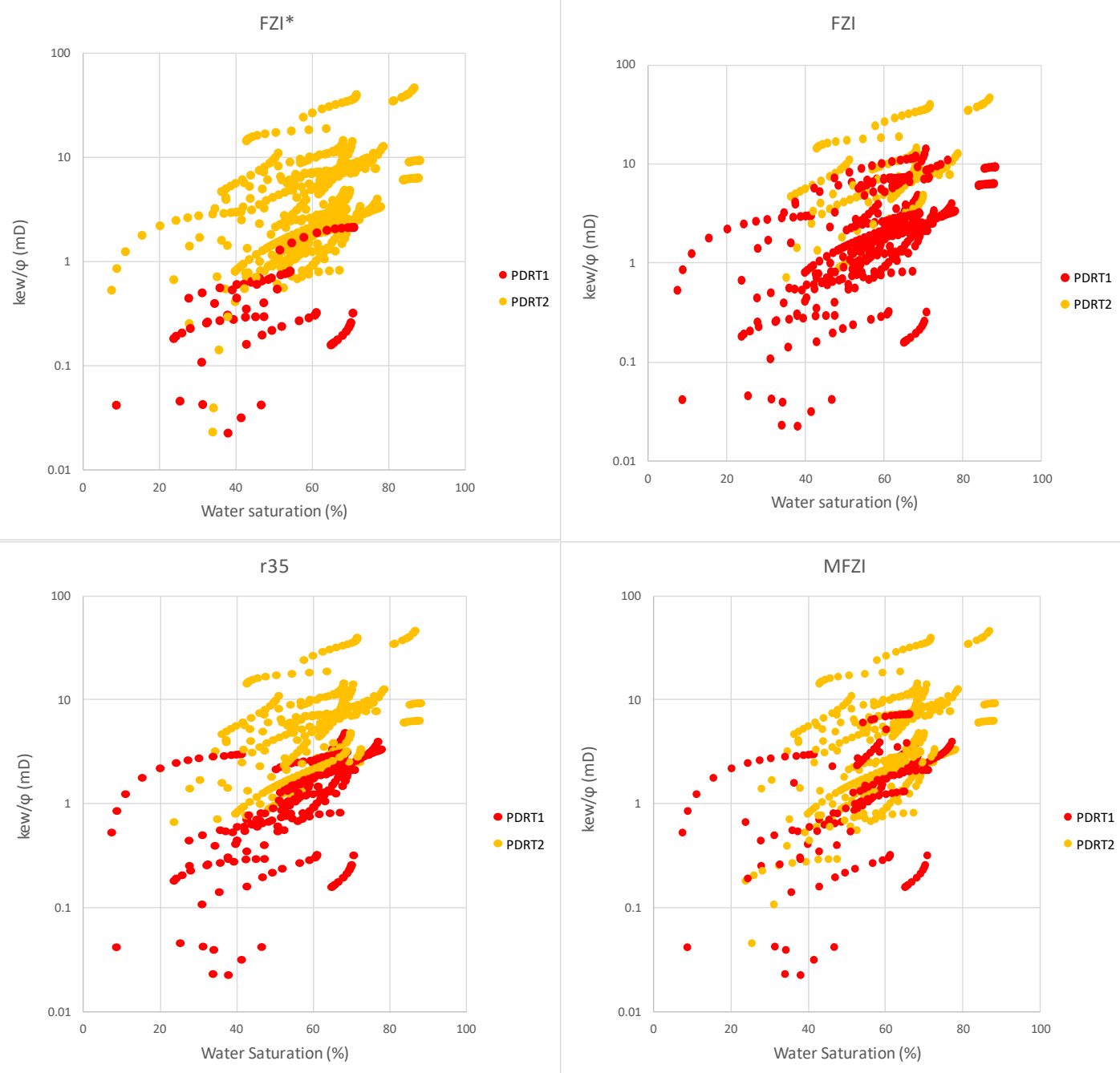
403 Figure 7 Identification of PDRTs using water $\frac{\boldsymbol{k}_{\boldsymbol{e}}}{\boldsymbol{\phi}}$ data by FZI* (top left), FZI (top right), MFZI (bottom right), and Winland r35 (bottom left).
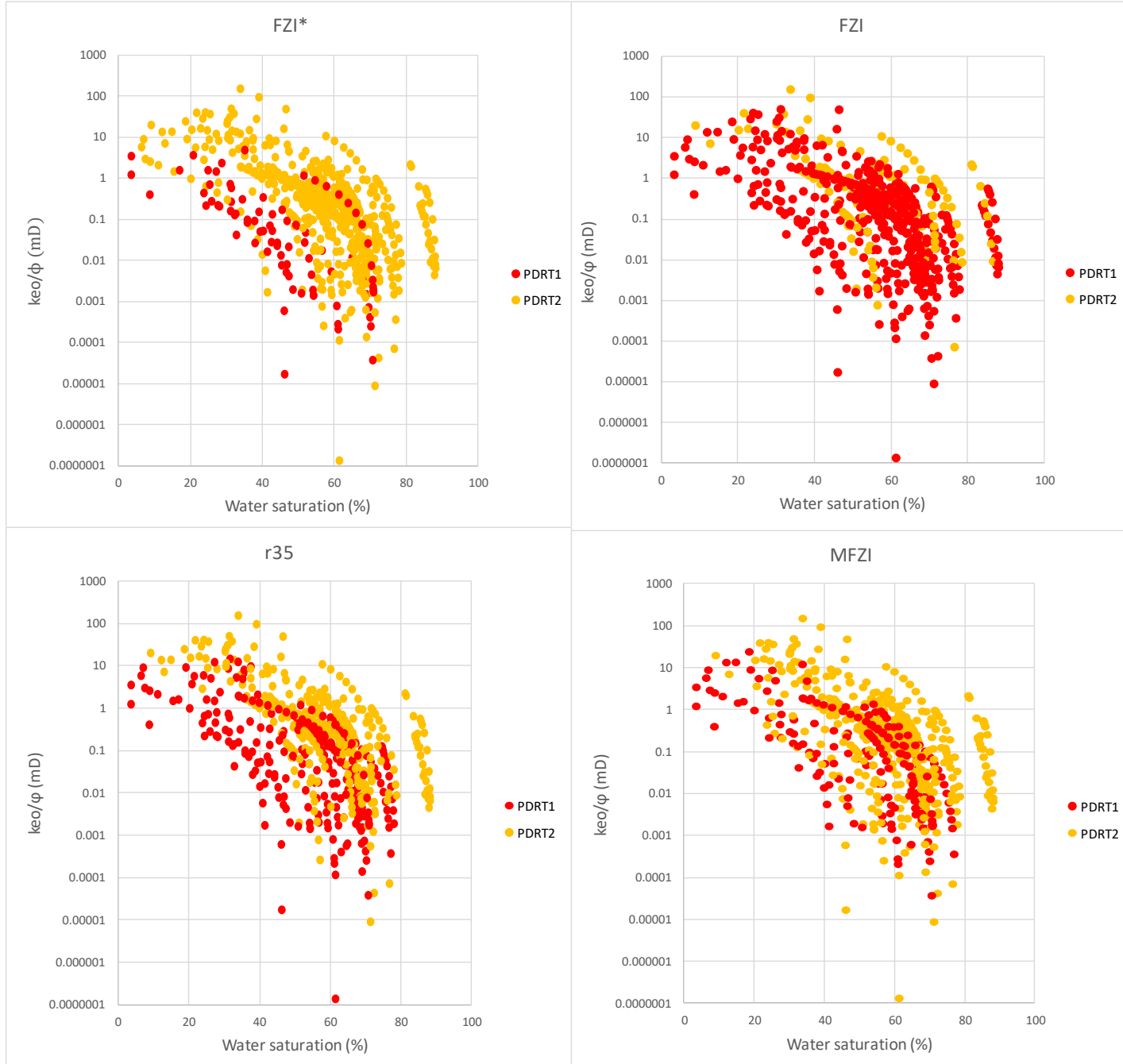

Figure 8 Identification of PDRTs using oil $\frac{\boldsymbol{k}_{\boldsymbol{e}}}{\boldsymbol{\phi}}$ data by FZI* (top left), FZI (top right), MFZI (bottom right), and Winland r35 (bottom left).

408 The correlation between four different indices and $\frac{k_{e w}}{\phi}$ at $S_{o r}$ is displayed in Supplementary

409 Material. All indices showed an increasing trend as $\frac{k_{e w}}{\phi}$ increased. FZI* and Winland r35 are 410 found with the highest $R^{2}$ values of 0.83 and 0.84 , respectively while $R^{2}$ of FZI and MFZI were 4110.35 and 0.38 , respectively. All indices also increased when $\frac{k_{e o}}{\phi}$ at $S_{\mathrm{wi}}$ increased. In this regard,

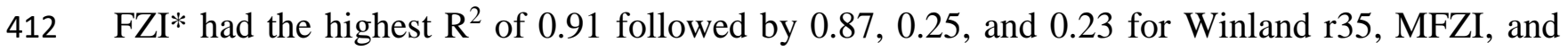
413 FZI; respectively. While plotting the indices vs. $\frac{\mathrm{k}_{\mathrm{e}}}{\phi}$ at the cross-over point, the point at which $\mathrm{k}_{\mathrm{ew}}$ 
$414=\mathrm{k}_{\mathrm{eo}}, \mathrm{FZI}^{*}$, and Winland $\mathrm{r} 35$ generated almost identical $\mathrm{R}^{2}$ values of 0.81 and 0.82 whereas $\mathrm{R}^{2}$ 415 values for FZI and MFZI were 0.34 and 0.38 ; much lower than the other two.

416 Based on Table 1, exponential and logarithmic equations were found to better fit water and oil $\frac{k_{e}}{\phi}$ 417 data, respectively. Regarding the water $\frac{k_{e}}{\phi}$ data in Supplementary Material, the relationship 418 between different indices and $\mathrm{C}_{7}$ shows that all indices increase as this attribute increases. MFZI, 419 FZI, Winland r35, and FZI* each produced $\mathrm{R}^{2}$ values of $0.59,0.55,0.49$, and 0.41 , respectively. 420 We did not observe any meaningful relationship between the indices and $\mathrm{C}_{8}$. Furthermore, 421 regarding each index vs. $\mathrm{C}_{9}$, an increasing trend for $\mathrm{FZI}^{*}$ and Winland $\mathrm{r} 35$ with the correlation 422 coefficients 0.73 and 0.72 was found, respectively.

\section{4.2.2. Gas-oil relative permeability data}

424 We continued the analysis of PDRTs through gas/oil effective permeabilities for each index 425 displayed in Figure 9 and 10. From the comparison of these figures it can be concluded that FZI* 426 performed much better in separating PDRTs compared to other indices. 

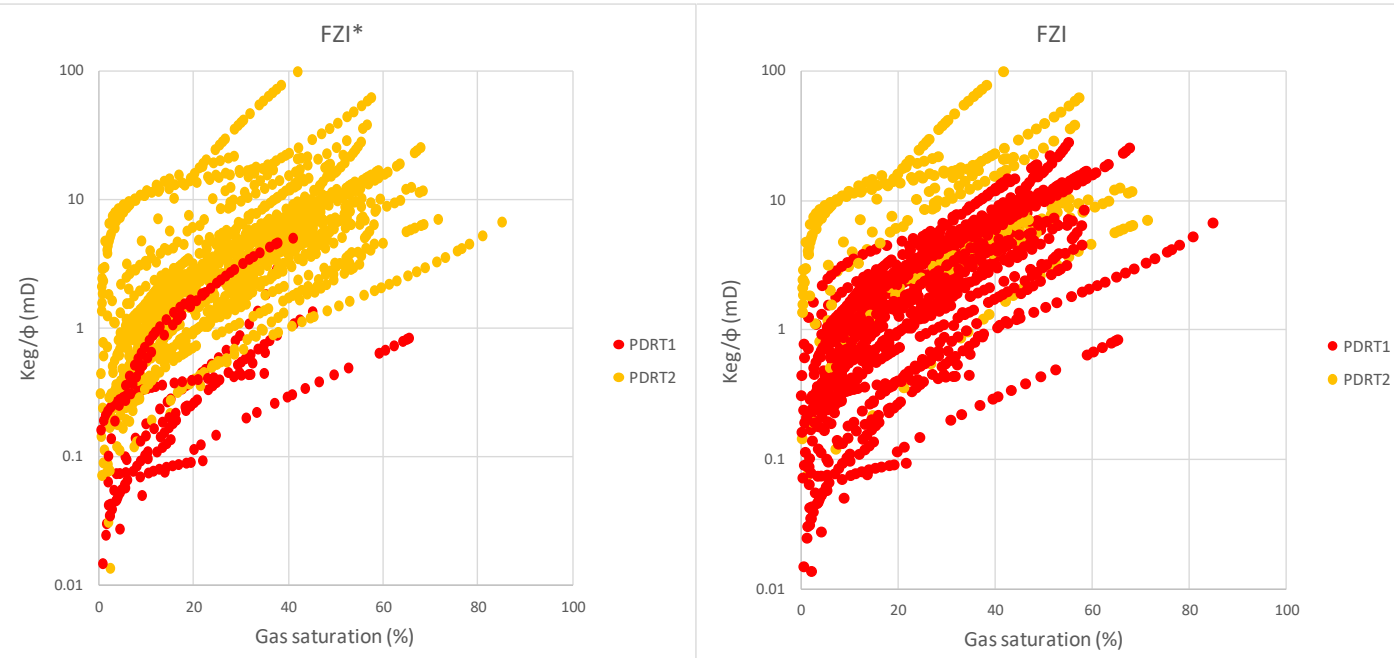

429 Figure 9 PDRTs using gas $\frac{\boldsymbol{k}_{\boldsymbol{e}}}{\boldsymbol{\phi}}$ data by FZI* (top left), FZI (top right), MFZI (bottom right), and 430 Winland r35 (bottom left). 

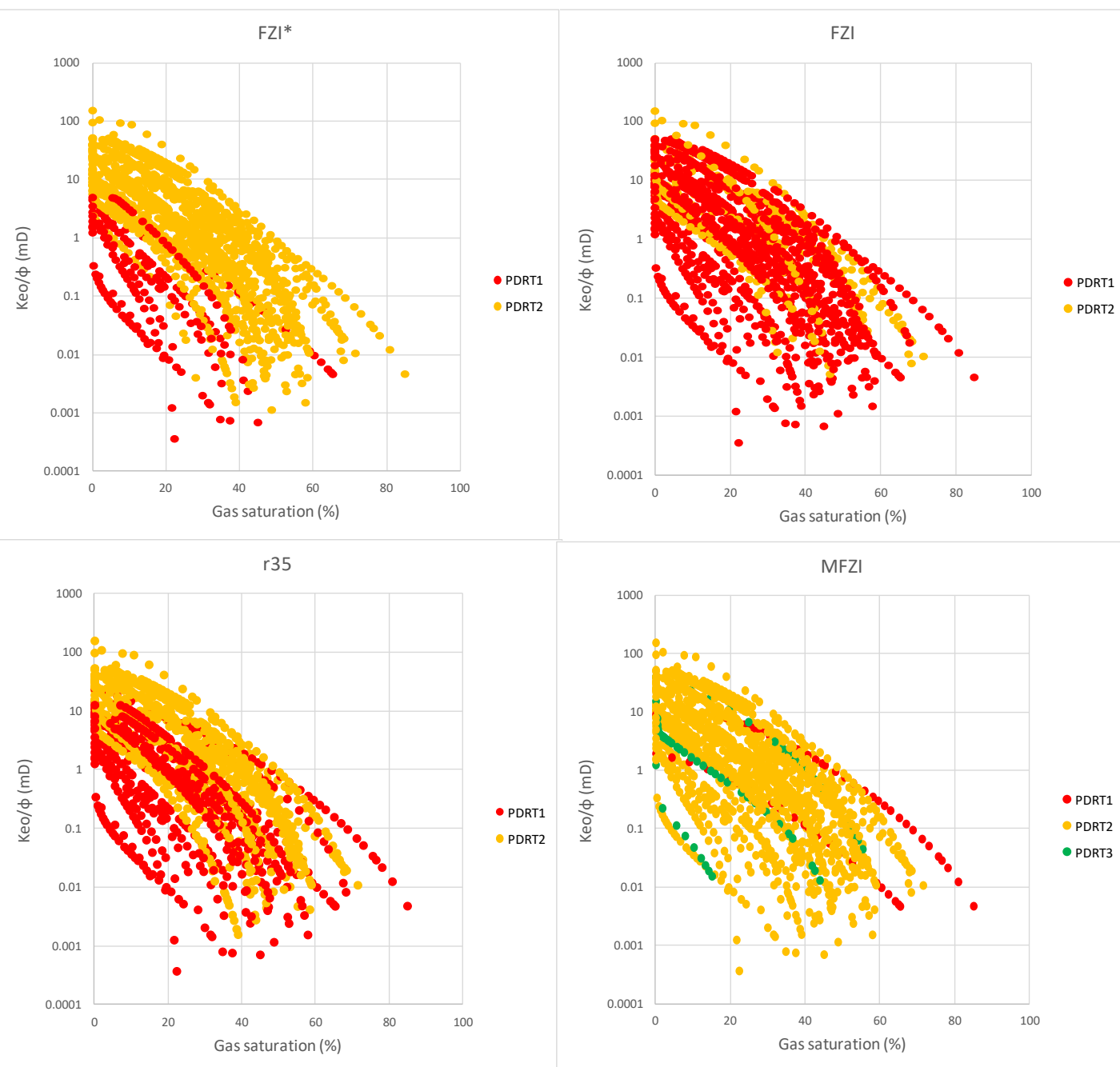

433 Figure 10 PDRTs using oil $\frac{\mathbf{k}_{\mathbf{e}}}{\mathbf{\phi}}$ data by FZI* (top left), FZI (top right), MFZI (bottom right), and Winland r35 (bottom left).

435 Effective permeability data is controlled strongly by pore structure. In this study, the end-point $436 \frac{k_{e g}}{\phi}$ (i.e., at residual liquid saturation), end-point $\frac{k_{e o}}{\phi}$, and $\frac{\mathrm{k}_{\mathrm{e}}}{\phi}$ at the cross-over point are considered 437 as representative effective permeability data to investigate their relationships with the indices. 438 See Supplementary Material for the correlation between indices and the end-point $\frac{k_{e g}}{\phi}$ data. It 439 was found that all indices increase as the end-point $\frac{k_{e g}}{\phi}$ increases where FZI* and Winland r35 440 are associated with the highest $R^{2}$ values of 0.71 and 0.74 , respectively, and FZI and MFZI with 441 the lowest $R^{2}$ values of 0.31 and 0.04 , correspondingly. Moreover, all indices increase as the 442 end-point $\frac{k_{e o}}{\phi}$ increases, where FZI* has the highest $\mathrm{R}^{2}$ of 0.94 followed by $R^{2}$ values of 0.89 , 
4430.24 , and 0.03 for Winland r35, FZI, and MFZI, respectively (see Supplementary Material).

444 When plotting the indices vs. $\frac{k_{\mathrm{e}}}{\phi}$ at the cross-over point, as shown in Supplementary Material,

$445 \quad$ FZI $^{*}$ and Winland r35 generated significantly better results than the FZI and MFZI.

446 Exponential models were better fitted to gas and oil $\frac{k_{e}}{\phi}$ data (Table 1). Relationships between

447 different indices and $\mathrm{C}_{10}$ and $\mathrm{C}_{11}$ are shown in Supplementary Material. It was found that as $\mathrm{C}_{10}$ 448 increases all indices increase with $\mathrm{FZI}^{*}$ showing the highest correlation coefficient. In regards to $449 \mathrm{C}_{11}, \mathrm{FZI}^{*}$, and Winland r35 showed an increasing trend whereas FZI and MFZI showed a 450 decreasing trend. Supplementary Material depicts the relationships between different indices 451 with $\mathrm{C}_{12}$ and $\mathrm{C}_{13}$, respectively. As $\mathrm{C}_{12}$ increases all indices increases as well, with Winland r35 452 followed by FZI* and FZI presenting the best performances. Similar to $\mathrm{C}_{11}$, as $\mathrm{C}_{13}$ increased, 453 FZI* and Winland r35 both increased as well, while FZI and MFZI decreased.

454 The details of correlation coefficients found in plotting different indices vs. constants/attributes 455 are summarized in Table 2. In 13 out of 25 cases FZI* produced the highest $\mathrm{R}^{2} \mathrm{~s}$ while in 8 cases 456 Winland r35 gave the highest correlation coefficients. In addition in 4 cases these two indices 457 almost matched. This reveals that theoretically-based FZI* and empirical Winland r35 result in 458 the highest $\mathrm{R}^{2} \mathrm{~s}$ with the FZI* out-performing the Winland r35. Mirzaei-Paiaman et al., (2018) 459 showed that almost all empirical indices, including Winland r35, have a similar mathematical 460 format and can be considered as the special solution of our proposed FZI*/PSRTI model. Among 461 these special solutions Winland r35 showed an acceptable performance in our case. It should be 462 emphasized here that Winland r35, since is empirical, may not have such a good performance in 463 other reservoirs and this requires further investigation.

464

465

466

467

468

469

470

471 
Table 2 Correlation coefficients between different indices and petrophysical parameters

\begin{tabular}{|c|c|c|c|c|c|}
\hline Test & Parameter & FZI* & FZI & MFZI & $\begin{array}{c}\text { Winland } \\
\text { r35 }\end{array}$ \\
\hline \multirow{5}{*}{$\begin{array}{c}\text { Primary drainage mercury injection } \\
\text { capillary pressure data }\end{array}$} & Threshold pressure & 0.66 & 0.01 & - & 0.61 \\
\hline & Measured r35 & 0.84 & 0.05 & - & 0.84 \\
\hline & Area under the capillary pressure curve & 0.67 & 0.16 & - & 0.59 \\
\hline & $\mathrm{C}_{1}$ & 0.75 & 0.05 & - & 0.76 \\
\hline & $\mathrm{C}_{2}$ & 0.71 & 0.10 & - & 0.73 \\
\hline \multirow{2}{*}{$\begin{array}{c}\text { Primary drainage water-oil capillary } \\
\text { pressure data }\end{array}$} & Connate water saturation & 0.58 & 0.03 & 0.57 & 0.48 \\
\hline & $\mathrm{C}_{3}$ & 0.53 & 0.04 & 0.20 & 0.47 \\
\hline \multirow{2}{*}{$\begin{array}{l}\text { Primary drainage gas-oil capillary } \\
\text { pressure data (non-zero connate water } \\
\text { saturation) }\end{array}$} & Residual liquid saturation & 0.97 & 0.93 & 0.73 & 0.97 \\
\hline & $\mathrm{C}_{4}$ & 0.52 & 0.29 & 0.11 & 0.51 \\
\hline \multirow{3}{*}{$\begin{array}{l}\text { Primary drainage gas-oil capillary } \\
\text { pressure data (zero connate water } \\
\text { saturation) }\end{array}$} & Residual oil saturation & 0.20 & 0.12 & 0.33 & 0.20 \\
\hline & $\mathrm{C}_{5}$ & 0.64 & 0.01 & 0.20 & 0.55 \\
\hline & $\mathrm{C}_{6}$ & 0.44 & 0.19 & 0.07 & 0.45 \\
\hline \multirow{6}{*}{ Water-oil relative permeability data } & End-point $\frac{\mathrm{k}_{\mathrm{ew}}}{\phi}$ & 0.83 & 0.35 & 0.38 & 0.84 \\
\hline & End-point $\frac{\mathrm{k}_{\mathrm{eo}}}{\phi}$ & 0.91 & 0.23 & 0.25 & 0.87 \\
\hline & Cross-over point $\frac{\mathrm{k}_{\mathrm{e}}}{\phi}$ & 0.81 & 0.34 & 0.38 & 0.82 \\
\hline & $\mathrm{C}_{7}$ & 0.41 & 0.55 & 0.59 & 0.49 \\
\hline & $\mathrm{C}_{8}$ & 0.00 & 0.06 & 0.14 & 0.00 \\
\hline & $\mathrm{C}_{9}$ & 0.73 & 0.20 & 0.25 & 0.72 \\
\hline \multirow{7}{*}{ Gas-oil relative permeability data } & End-point $\frac{\mathrm{k}_{\mathrm{eg}}}{\phi}$ & 0.71 & 0.31 & 0.04 & 0.74 \\
\hline & End-point $\frac{\mathrm{k}_{\mathrm{eo}}}{\phi}$ & 0.94 & 0.24 & 0.03 & 0.89 \\
\hline & Cross-over point $\frac{\mathrm{k}_{\mathrm{e}}}{\phi}$ & 0.76 & 0.33 & 0.05 & 0.74 \\
\hline & $\mathrm{C}_{10}$ & 0.53 & 0.09 & 0.02 & 0.49 \\
\hline & $\mathrm{C}_{11}$ & 0.12 & 0.01 & 0.16 & 0.09 \\
\hline & $\mathrm{C}_{12}$ & 0.67 & 0.34 & 0.05 & 0.73 \\
\hline & $\mathrm{C}_{13}$ & 0.08 & 0.02 & 0.21 & 0.06 \\
\hline
\end{tabular}

\section{5. Conclusions}

475 In this paper, we attempted to compare the accuracy of previous (FZI, Winland r35, and MFZI)

476 and recent (FZI* and PSRTI) petrophysical rock typing indices in appraisal of static and dynamic

477 rock groups by utilizing a significant amount of SCAL data from a heterogeneous carbonate

478 formation. Based on our analyses the following 6 conclusions can be drawn: 
1- In many practical circumstances, static and dynamic rock types are not the same and exhibit significant differences. Although the previous methods fail in recognizing such differences, the FZI* and PSRTI are able to distinguish between static and dynamic rock types.

2- The indices FZI* and PSRTI can identify various groups of static and dynamic rock types better than the existing ones. The occasional underperformance of these two indices could mainly be attributed to lack of some essential petrophysical data such as effective connected porosity, tortuosity, and shape factor. Cleaning and aging procedures could be other factors affecting the rock typing outcome.

3- Regarding the correlation between various indices and several petrophysical attributes, FZI* and PSRTI give the most acceptable results.

4- The PSRTs and PDRTs identified by PSRTI and FZI*, respectively, can be used with high confidence in water saturation-height calculations and fluid displacement simulation processes.

5- Saturation functions (e.g., water-oil capillary pressure) cannot always be modeled using a specific form of a mathematical function (e.g. exponential model).

6- Among the special solutions of the FZI* (e.g., FZI, MFZI, and Winland r35) the empirical Winland r35 showed an acceptable performance in rock typing study. This index may not have such a good performance in other reservoirs and needs further investigations.

\section{Acknowledgements}

The first and second authors thank National Iranian South Oil Company (NISOC) and National Iranian Oil Company (NIOC) for permission to publish this work. This work is also partly supported by NSERC/Energi Simulation and Alberta Innovates Chairs.

\section{References}

Abbaszadeh, M., Fujii, H., Fujimoto, F., 1996. Permeability Prediction by Hydraulic Flow Units -Theory and Applications. SPE Formation Evaluation 11, 263-271.

Aguilera, R. 2002. Incorporating capillary pressure, pore throat aperture radii, height above freewater table, and Winland r35 values on Pickett plots. AAPG Bulletin, v. 86, no. 4 (April 2002), pp. 605-624

Amaefule, J.O., Altunbay, M., Tiab, D., Kersey, D.G., Keelan, D.K., 1993. Enhanced reservoir description using core and log data to identify hydraulic flow units and predict permeability in uncored intervals/wells. In: SPE Annual Technical Conference and Exhibition, 3-6 October, Houston, Texas. 
Anderson, W.G. 1987. Wettability Literature Survey-Part 4: Effects of Wettability on Capillary Pressure, Journal of Petroleum Technology 39, 10. DOI https://doi.org/10.2118/15271PA

Askari, A.A., Behrouz, T., 2011. A Fully Integrated Method for Dynamic Rock Type Characterization Development in One of Iranian Off-Shore Oil Reservoir. Journal of Chemical and Petroleum Engineering, University of Tehran, Vol. 45, No.2, PP. 83-96

Carman, P.C., 1937. Fluid flow through granular beds. Trans. Inst. Chem. Eng. 15, 150-166.

Chen, X., and Yao, G. 2017. An improved model for permeability estimation in low permeable porous media based on fractal geometry and modified Hagen-Poiseuille flow. Fuel 210, $748-757$.

Chen, X., and Zhou, Y. 2017. Applications of digital core analysis and hydraulic flow units in petrophysical characterization. Advances in Geo-energy Research. Vol. 1, No. 1, p. 1830, doi: 10.26804/ager.2017.01.02.

Ferreira, F.C., Booth, R., Oliveira, R., Carneiro, G., Bize-Forest, N., and Wahanik, H. 2005. New Rock-Typing Index Based on Hydraulic and Electric Tortuosity Data for MultiScale Dynamic Characterization of Complex Carbonate Reservoirs. SPE-175014-MS, SPE Annual Technical Conference and Exhibition, 28-30 September, Houston, Texas, USA. DOI https://doi.org/10.2118/175014-MS

Hamidpour, E., Mirzaei-Paiaman, A., Masihi, M., Harimi, B., 2015. Experimental study of some important factors on nonwetting phase recovery by cocurrent spontaneous imbibitions. Journal of Natural Gas Science \& Engineering 27 (2), 1213-1228. http://dx.doi.org/10.1016/j.jngse.2015.09.070

Harimi, B., Masihi, M., Mirzaei-Paiaman, A., and Hamidpour, E. 2018. Experimental study of dynamic imbibition during water flooding of naturally fractured reservoirs. Journal of Petroleum Science and Engineering, https://doi.org/10.1016/j.petrol.2018.11.008

Izadi, M., Ghalambor, A., 2013. New approach in permeability and hydraulic-flow unit determination. SPE Reserv. Eval. Eng. 16 (3), 257-264.

Kolodzie, S. 1980. Analysis of pore throat size and use of the Waxman-Smits equation to determine OOIP in Spindle field, Colorado. SPE-9382-MS, SPE Annual Technical Conference and Exhibition, 21-24 September, Dallas, Texas. DOI https://doi.org/10.2118/9382-MS

Kozeny, J., 1927. ber kapillare Leitung des Wassers im Boden, Sitzungsberichte.Royal Academy of Science Vienna, Proc. Class I, 136, 271-306.

Lin, B., Chen, M., and Pang, H. 2015. Modeling pore size distribution of southern Sichuan shale gas reservoirs. Journal of Natural Gas Science and Engineering Volume 26, Pages 883894.

Mirzaei-Paiaman A, Saboorian-Jooybari H. 2016. A method based on spontaneous imbibition for characterization of pore structure: application in pre-SCAL sample selection and rock typing. J Nat Gas Sci Eng 35:814-25. http://dx.doi.org/10.1016/j.jngse.2016.09.023.

Mirzaei-Paiaman, A., Dalvand, K., Oraki Kohshour, I., Masihi, M., and Moghadasi, J. 2010. A Study on the Key Influential Factors of a Gas Reservoir's Potential for Aqueous Phase Trapping. Energy Sources, Part A: Recovery, Utilization, and Environmental Effects, Volume 34, Issue 16, Pages 1541-1549. https://doi.org/10.1080/15567036.2010.489102 
Mirzaei-Paiaman, A., Masihi, M., Standnes, D.C. (2013) Index for characterizing wettability of reservoir rocks based on spontaneous imbibition recovery data. Energy Fuels 27: 7360 7368, DOI: dx.doi.org/10.1021/ef401953b

Mirzaei-Paiaman, A., Ostadhassan, M., Rezaee, R., Saboorian-Jooybari, H., and Chen, Z. 2018. A New Approach in Petrophysical Rock Typing. Journal of Petroleum Science and Engineering, 166, 445-464. https://doi.org/10.1016/j.petrol.2018.03.075

Mirzaei-Paiaman, A., Saboorian-Jooybari, H., Pourafshari, P., 2015. Improved method to identify hydraulic flow units for reservoir characterization. Energy Technol. 3 (7), 726733.

Nooruddin, H., Hossain, M., 2011. Modified Kozeny-Carmen correlation for enhanced hydraulic flow unit characterization. J. Petroleum Sci. Eng. 80, 107-115.

Oliveira, G.P., Roque, W.L., Araújo, E.A., Diniz, A.A.R., Simões, T.A., Santos, M.D. 2016. Competitive placement of oil perforation zones in hydraulic flow units from centrality measures. Journal of Petroleum Science and Engineering, 147, 282-291. DOI https://doi.org/10.1016/j.petrol.2016.06.008

Pittman, E. D., 1992, Relationship of porosity and permeability to various parameters derived from mercury injection-capillary pressure curves for sandstone: AAPG Bulletin, 76, 191198.

Rabiller, P., 2017. Combining porosimetry and Purcell permeability modeling to calibrate FZI and define a dynamic permeability cut-off. International Symposium of the Society of Core Analysis, Vienna, Austria, 27-30 August 2017.

Rebelle, M. 2014. Rock-typing In Carbonates: A Critical Review Of Clustering Methods. SPE171759-MS, Abu Dhabi International Petroleum Exhibition and Conference, 10-13 November, Abu Dhabi, UAE.

Roque, W.L., Oliveira, G.P., Santos, M.D., and Simões, T.A. 2017. Production zone placements based on maximum closeness centrality as strategy for oil recovery. Journal of Petroleum Science and Engineering, 156, 430-441. DOI: 10.1016/j.petrol.2017.06.016

Saboorian-Jooybari, H., 2017. A structured mobility-based methodology for quantification of net-pay cutoff in petroleum reservoirs. SPE-183643-PA. SPE Reservoir Evaluation \& Engineering, 20 (02), 1-17.

Saboorian-Jooybari, H., Mowazi, G.H., Jaberi, S.R., 2010. A New Approach for Rock Typing Used in One of the Iranian Carbonate Reservoir (A Case Study). In: Paper SPE 131915 Presented at the International Oil and Gas Conference and Exhibition, Beijing, China, 810 June.

Serag El Din, S., Dernaika, M.R., and Kalam, Z. 2014. Integration of Petrophysical SCAL Measurements for Better Understanding Heterogeneity Effects in Carbonates: Case Study Using Samples from a Super Giant Field in Abu Dhabi. IPTC-17572-MS, International Petroleum Technology Conference, 19-22 January, Doha, Qatar.

Shen, L. and Chen, Z. 2007. Critical review of the impact of tortuosity on diffusion, Chemical Engineering Science 62, 3748-3755.

Siddiqui, S., Okasha, T.M., Funk, J.J., and Al-Harbi, A.M. 2006. Improvements in the selection criteria for the representative special core analysis samples. SPE-84302-PA, SPE Reservoir Evaluation \& Engineering, 9 (6), 647-653. DOI https://doi.org/10.2118/84302PA 
600 Thomeer, J.H.M. 1960. Introduction of a Pore Geometrical Factor Defined by the Capillary 601 Pressure Curve. J Pet Technol 12 (3): 73-77. SPE-1324$602 \quad$ G. http://dx.doi.org/10.2118/1324-G

603 Xu, C., Torres-Verdín, C. 2013. Pore System Characterization and Petrophysical Rock 604 Classification Using a Bimodal Gaussian Density Function. Math Geosci DOI $605 \quad 10.1007 / \mathrm{s} 11004-013-9473-2$ 